\title{
YAP/TAZ REGULATES THE EXPRESSION OF PROTEOGLYCAN 4 AND TENASCIN C IN SUPERFICIAL-ZONE CHONDROCYTES
}

\author{
E. Delve ${ }^{1,2}$, V. Co ${ }^{3}$, S.C. Regmi ${ }^{4}$, J. Parreno ${ }^{1,5}$, T.A. Schmidt ${ }^{6}$ and R.A. Kandel ${ }^{1,2,7,8, *}$ \\ ${ }^{1}$ Lunenfeld-Tanenbaum Research Institute, Mount Sinai Hospital, Toronto, Canada \\ ${ }^{2}$ Institute of Biomaterials and Biomedical Engineering, University of Toronto, Toronto, Canada \\ ${ }^{3}$ Faculty of Science, University of Ontario Institute of Technology, Oshawa, Canada \\ ${ }^{4}$ Faculty of Kinesiology, University of Calgary, Calgary, Canada \\ ${ }^{5}$ Department of Molecular Medicine, The Scripps Research Institute, La Jolla, CA, USA \\ ${ }^{6}$ Biomedical Engineering Department, University of Connecticut Health Center, Farmington, CN, USA \\ ${ }^{7}$ Laboratory Medicine and Pathobiology, University of Toronto, Toronto, Canada \\ ${ }^{8}$ Pathology and Laboratory Medicine, Mount Sinai Hospital, Toronto, Canada
}

\begin{abstract}
The roles of cell division control protein 42 homologue (CDC42) and actin polymerisation in regulating the phenotype of superficial-zone chondrocytes (SZCs) have been demonstrated in vitro; however, the signalling pathway(s) downstream have yet to be fully elucidated. The study hypothesis was that Yes-associated protein (YAP) and transcriptional co-activator with PDZ-binding motif (TAZ) act downstream to regulate proteoglycan 4 (PRG4) and tenascin C (TNC). Bovine SZCs grown in monolayer were treated with ML141 (CDC42 inhibitor) or the actin depolymerising agents, latrunculin B and cytochalasin D, to determine the effect on YAP/TAZ. Verteporfin (YAP/TAZ inhibitor) and YAP/TAZ siRNA-mediated knockdown were used to determine their role in regulating PRG4 and TNC. ML141 treatment reduced total YAP/TAZ protein, nuclear TAZ levels and the YAP/TAZ target gene, connective tissue growth factor (CTGF) mRNA levels. Latrunculin B decreased nuclear TAZ, while cytochalasin D treatment trended towards increased nuclear TAZ $(p=0.06)$, correlating with decreased and increased CTGF mRNA levels, respectively. Verteporfin treatment decreased PRG4 and TNC expression, with no effect on actin polymerisation. siRNA-mediated knockdown of YAP/TAZ revealed that PRG4 was regulated by YAP/TAZ while TNC was regulated by TAZ only. As cytochalasin D can activate myocardin-related transcription factor-A (MRTF-A), siRNA-mediated knockdown was performed to determine the role of $M R T F-A$ in regulating YAP/TAZ. Although nuclear TAZ decreased, no significant changes in total protein levels were observed. Findings suggested that CDC42 and actin polymerisation regulated SZCs through multiple actin-regulated pathways. Understanding the regulation of these chondroprotective molecules may have important implications for prevention/treatment of osteoarthritis.
\end{abstract}

Keywords: Cell division control protein 42 homologue, actin polymerisation, superficial-zone chondrocyte, primary chondrocyte phenotype, proteoglycan 4, tenascin C, Yes-associated protein, transcriptional coactivator with PDZ-binding motif, myocardin-related transcription factor-A.

*Address for correspondence: Rita A. Kandel, MD, Department of Pathology and Laboratory Medicine, Mount Sinai Hospital, 600 University Avenue, Suite 6-500, Toronto, M5G 1X5, Ontario, Canada.

Telephone number: +1 4165868516 Email: rita.kandel@sinaihealthsystem.ca

Copyright policy: This article is distributed in accordance with Creative Commons Attribution Licence (http://creativecommons.org/licenses/by-sa/4.0/).

\section{List of Abbreviations}

BCA

CDC42

CTGF bicinchoninic acid protein

cell division control protein 42

homolog

connective tissue growth factor

\section{DAPI \\ DMEM \\ DMSO \\ DZ \\ ELISA}

4',6-diamidino-2-phenylindole

Dulbecco's modified Eagle medium dimethyl sulphoxide deep zone enzyme-linked immunosorbent assay 


\begin{tabular}{|c|c|}
\hline F-actin & filamentous actin \\
\hline G-actin & globular actin \\
\hline GAPDH & $\begin{array}{l}\text { glyceraldehyde 3-phosphate } \\
\text { dehydrogenase }\end{array}$ \\
\hline GSK3 & glycogen synthase kinase 3 \\
\hline HRP & horseradish peroxidase \\
\hline IL-1 $\beta$ & interleukin 1 beta \\
\hline ITS & insulin-transferrin-selenium \\
\hline LATS & large tumour suppressor kinase \\
\hline MRTF-A & $\begin{array}{l}\text { myocardin-related transcription } \\
\text { factor A }\end{array}$ \\
\hline $\mathrm{OA}$ & osteoarthritis \\
\hline PBS & phosphate-buffered saline \\
\hline PRG4 & proteogylcan 4 \\
\hline RIPA & radioimmunoprecipitation assay \\
\hline Rac1 & $\begin{array}{l}\text { Ras-related C3 botulinum toxin } \\
\text { substrate } 1\end{array}$ \\
\hline ROCK & Rho-associated protein kinase \\
\hline SDS-PAGE & $\begin{array}{l}\text { sodium dodecyl sulphate } \\
\text { polyacrylamide gel electrophoresis }\end{array}$ \\
\hline SD & standard deviation \\
\hline siRNA & small interfering ribonucleic acid \\
\hline sit & TAZ siRNA \\
\hline siY & YAP siRNA \\
\hline siYT & YAP and TAZ siRNA \\
\hline Sox9 & sex-determining region Y-box 9 \\
\hline SZ & superficial zone \\
\hline SZC & superficial-zone chondrocyte \\
\hline TAZ & $\begin{array}{l}\text { transcriptional co-activator with } \\
\text { PDZ-binding motif }\end{array}$ \\
\hline TEAD & TEA-domain \\
\hline TGF- $\beta 1$ & transforming growth factor beta 1 \\
\hline TNC & tenascin $\mathrm{C}$ \\
\hline TNF- $\alpha$ & tumour necrosis factor alpha \\
\hline YAP & Yes-associated protein \\
\hline
\end{tabular}

\section{Introduction}

Cell shape is a critical regulator of chondrocyte phenotype. Most studies contributing to the understanding of how cell shape regulates chondrocyte phenotype are those characterising chondrocyte dedifferentiation during monolayer culture. As primary chondrocytes are passaged, they lose expression of the cartilage matrix molecules, collagen type II and aggrecan, and acquire an elongated morphology concomitant with increased expression of collagen type I and TNC (Benya and Shaffer, 1982; Darling and Athanasiou, 2006; Mallein-Gerin et al., 1990; Parreno et al., 2014). This process is mediated by the formation of actin stress fibres, increased expression and nuclear localisation of MRTF-A (Parreno et al., 2014; Parreno et al., 2016) and loss of adseverin expression (Chan et al., 2019). However, these studies typically use fullthickness chondrocytes, which have mostly a round morphology unlike SZCs, which exhibit an elongated morphology in native cartilage (Brighton et al., 1984).

The SZ of articular cartilage accounts for merely 10$20 \%$ of the tissue and exhibits unique characteristics including elongated chondrocyte morphology, collagen fibres oriented parallel to the articular surface and expression of zone-specific molecules (Aydelotte and Kuettner, 1988; Khan et al., 2001; Malda et al., 2010; Schumacher et al., 1994; Sophia Fox et al., 2009). In mature cartilage, these unique features of the SZ participate in cartilage function by contributing to biomechanical stability and metabolic homeostasis of the tissue, in part through expression of PRG4 and TNC. PRG4 is a marker of progenitor cells as well as differentiated SZCs and expression of the interzone marker, TNC, also persists in the SZ after cartilage maturation (Decker et al., 2017; Pacifici et al., 1993; Pfander, 2004). Both PRG4 and TNC have demonstrated chondroprotective roles against the development of OA in vivo (Coles et al., 2010; Flannery et al., 2009; Matsui et al., 2018; Okamura et al., 2010; Rhee et al., 2005; Ruan et al., 2013). Deregulation of articular cartilage homeostasis can lead to cartilage degradation and onset of OA (Loeser et al., 2016). Although the exact pathogenesis of OA is not fully elucidated, loss of the SZ is one of the earliest changes observed (Guilak et al., 1994; Pritzker et al., 2006).

As SZCs have an elongated morphology in native cartilage, a body of literature is beginning to emerge investigating the role of cell shape in the regulation of the SZC phenotype. While cell shape can be regulated by multiple cytoskeletal elements, microarray analysis comparing the expression levels between SZ and DZ chondrocytes determined SZCs more highly express molecules involved in CDC42 signalling and actin polymerisation (Grogan et al., 2013). In a previous study, Delve et al. (2018) partially elucidated the downstream signalling pathway linking CDC42 and actin polymerisation to the regulation of PRG4 and TNC by demonstrating the involvement of the actin-regulated transcription co-factor, MRTF-A. However, siRNA knockdown of MRTF-A decreases TNC expression but does not appear to regulate PRG4 expression, suggesting that a different actin-regulated signalling pathway may be involved (Delve et al., 2018).

In addition to regulating MRTF-A, CDC42 and actin polymerisation regulate YAP and TAZ localisation in other cell types (Aragona et al., 2013; Foster et al., 2012; Reginensi et al., 2013). YAP and TAZ are structurally similar transcriptional co-factors involved in multiple cellular processes including proliferation, organ growth and stem cell differentiation (Low et al., 2014). YAP/TAZ translocates from the cytoplasm to the nucleus in response to increased extracellular matrix stiffness, cell shape (increased cell spreading) and actin polymerisation (Dupont et al., 2011; Totaro et al., 2017). Unlike the nuclear/cytoplasmic localisation of MRTF-A, which is regulated by direct interaction with actin monomers, YAP/TAZ regulation by actin polymerisation is thought to occur indirectly (Zhao et al., 2011). YAP/TAZ localisation is also regulated by the canonical Hippo pathway; however, activation of this pathway leads to inactivation of 
YAP/TAZ through phosphorylation by LATS and binding to cytoplasmic retention factor 14-3-3, thus preventing nuclear translocation (Piccolo et al., 2014). Regulation of YAP/TAZ by mechanical cues occurs independently of the Hippo/LATS cascade (Dupont et al., 2011).

Although YAP and TAZ share sequence homology, they have structural differences that enable distinct cellular functions most notably observed with global deletion in mice. Global YAP deletion is lethal while global TAZ deletion leads to skeletal defects and polycystic kidney disease at maturity (Hossain et al., 2007; Morin-Kensicki et al., 2006). In other instances, YAP and TAZ knockdown demonstrates functional homology and compensatory roles (Miesfeld et al., 2015; Xin et al., 2013). The role of YAP/TAZ in chondrogenesis has been investigated and activation appears to inhibit chondrocyte proliferation, differentiation and maturation leading to chondrodysplasia (Goto et al., 2018). The mechanism elucidated by Goto et al. (2018) describes this inhibition as a result of YAP/TAZ interaction with TEA-domain leading to decreased expression of Sox9, the master regulator of chondrogenesis. Activation of YAP or TAZ leads to decreased expression of Sox9; YAP or TAZ deletion restores the phenotype, leading the authors to conclude that within this context no functional differences exist between YAP and TAZ (Goto et al., 2018). YAP/TAZ expression has been detected in full-thickness primary chondrocytes (Parreno et al., 2016); however, YAP/TAZ role in regulation of the $S Z$ primary chondrocyte phenotype has not been elucidated.

The aim of the present study was to investigate the role of YAP/TAZ downstream of CDC42 and actin polymerisation to further elucidate molecular mechanisms regulating PRG4 and TNC expression by SZCs. Due to the critical role the intact zonal architecture plays in maintaining cartilage homeostasis, understanding the regulation of the SZC phenotype and expression of the chondroprotective molecules PRG4 and TNC may contribute to the understanding of how to recapitulate the zonal architecture in tissue engineered cartilage constructs.

\section{Materials and Methods}

\section{Cell culture}

Chondrocytes from the articular cartilage SZ were harvested from metacarpal-phalangeal joints of 6-9 months old calves, as previously described (Delve et al., 2018). Briefly, the top 10-20\% of the tissue was harvested and cells were isolated by sequential enzymatic digestion with $0.5 \%$ protease (Sigma-Aldrich) for $45 \mathrm{~min}$, followed by 14-17 h with $0.1 \%$ collagenase (Roche). SZCs were grown in monolayer $\left(5.2 \times 10^{3}\right.$ cells $\left./ \mathrm{cm}^{2}\right)$ in high-glucose DMEM supplemented with $1 \%$ ITS+ (354351; BD Biosciences), $100 \mathrm{nM}$ dexamethasone (Sigma-Aldrich), $40 \mu \mathrm{g} / \mathrm{mL}$ proline (Sigma-Aldrich), $100 \mathrm{mM}$ pyruvate (Gibco) and $100 \mu \mathrm{g} / \mathrm{mL}$ ascorbic acid (Sigma-Aldrich) and culture at $37{ }^{\circ} \mathrm{C}$ with $5 \% \mathrm{CO}_{2}$. All analyses were performed within $5 \mathrm{~d}$ of cell seeding.

\section{Treatment with chemical inhibitors}

Following $24 \mathrm{~h}$ in culture, SZCs were treated with chemical inhibitors and harvested $24 \mathrm{~h}$ later for analysis (see Table 1 for chemical inhibitors and concentrations used). Optimal inhibitor concentrations were selected based on previous studies (Delve et al., 2018) or determined by performing concentration gradient experiments (data not shown). All chemical inhibitors were dissolved in DMSO (Sigma-Aldrich) and control cultures were treated with an equal volume of DMSO only.

\section{Gene expression}

Samples were harvested in TRIzol (Thermo Fisher Scientific) at various time points $(24 \mathrm{~h}, 3 \mathrm{~d}$ and $5 \mathrm{~d})$ and RNA was extracted according to the manufacturer's instructions. Superscript III Reverse Transcriptase (Life Technologies) was used to transcribe 500-1,000 ng of RNA. Polymerase chain reaction was performed with a LightCycler 96 RealTime PCR system (Roche) using gene-specific primers (Table 2). Mean relative quantification values were calculated by the Pfaffl method using the $18 \mathrm{~S}$ rRNA as housekeeping gene (Pfaffl, 2001) and expressed as a percentage as compared to control.

\section{Total protein extraction}

SZCs were harvested in RIPA buffer $(50 \mathrm{mM}$ Tris $\mathrm{HCl}$ pH 8.0, 150 mM NaCl, 1 \% NP-40, 0.5 \% sodium deoxycholate and $0.1 \%$ SDS) supplemented with cOmplete $^{\mathrm{TM}}$, Mini, EDTA-free Protease Inhibitor Cocktail (Roche Diagnostics) on ice, as described previously (Delve et al., 2018). Pierce ${ }^{\mathrm{TM}}$ BCA Protein Assay Kit (Thermo Fisher Scientific) was used to quantify total protein content.

\section{G-/F-actin assay}

G- and F-actin fractions were separated by Triton X-100 fractionation, as described previously (Delve et al., 2018; Papakonstani and Stournaras, 2002; Parreno et al., 2014). Briefly, Triton-soluble fraction containing the globular actin (G-actin) was isolated with extraction buffer [1 \% Triton X-100 in PBS without calcium or magnesium $\left({ }^{-} /\right)$] plus cOmplete ${ }^{\mathrm{TM}}$, Mini, EDTA-free Protease Inhibitor Cocktail (Roche Diagnostics). The Triton-insoluble fraction containing filamentous actin (F-actin) was harvested with an equal volume of RIPA buffer supplemented with cOmplete $^{\mathrm{TM}}$, Mini, EDTA-free Protease Inhibitor Cocktail (Roche Diagnostics). Equal volumes of Gand F-actin fractions were separated by SDS-PAGE as described below and probed for total actin using a pan-actin antibody. Densitometry was performed and the values for the G- and F-actin fractions were expressed as a percentage of the total actin (sum of G- and F-actin densitometry values). 
Table 1. List of chemical inhibitors.

\begin{tabular}{|c|c|c|c|}
\hline Molecule/pathway & Chemical inhibitor & Source & Concentration \\
\hline CDC42 & ML141 & Tocris & $10 \mu \mathrm{M}$ \\
\hline Actin depolymerisation & Latrunculin B & Enzo Life Sciences & $1 \mu \mathrm{M}$ \\
\hline Actin depolymerisation & Cytochalasin D & Enzo Life Sciences & $10 \mu \mathrm{M}$ \\
\hline YAP/TAZ & Verteporfin & Sigma-Aldrich & $1 \mu \mathrm{M}$ \\
\hline
\end{tabular}

Table 2. Gene-specific bovine primer sequences. F: forward. R: reverse.

\begin{tabular}{|c|c|}
\hline Gene & Primer sequence \\
\hline \multirow{2}{*}{ 18S rRNA } & $\begin{array}{c}\text { F: 5'-GTAACCCGTTGAACCCCATT-3' } \\
\text { R: 5'-CCATCCAATCGGTAGTAGCG-3' }\end{array}$ \\
\hline \multirow{2}{*}{ Proteoglycan 4 } & $\begin{array}{r}\text { F: 5'-ATGCCTGAACCGACTCCTAC-3' } \\
\text { R: 5'-TGCCGAAGCCTTGACTGG-3' }\end{array}$ \\
\hline \multirow{2}{*}{ Tenascin C } & $\begin{array}{c}\text { F: 5'-GGAACCTGCGGGCTGTGGAC-3' } \\
\text { R: 5'-CCCCGGATCACCCCGTGGAT-3' }\end{array}$ \\
\hline \multirow{2}{*}{ YAP } & F: 5'-CTCTCCCCGAAACGCAGT-3' \\
& R: 5'-AAGCAATTTCAGCGGACTGTA-3' \\
\hline \multirow{2}{*}{ TAZ } & F: 5'-ATGGCAAGACCCTAGGAAGG-3' \\
& R: 5'-CAAGATTCGGCTGAGACACG-3' \\
\hline
\end{tabular}

\section{Nuclear and cytoplasmic extraction}

Nuclear and cytoplasmic fractions were extracted using the NE-PER Nuclear and Cytoplasmic Extraction kit (Thermo Fisher Scientific), as described by the manufacturer with slight modifications. Briefly, SZCs were washed with $\mathrm{PBS}^{-}{ }^{-}$and $100 \mu \mathrm{L}$ cytoplasmic extraction buffer I was added to the plate and cells were scraped. The cytoplasmic fraction was separated by adding $5.5 \mu \mathrm{L}$ of cytoplasmic extraction buffer II. The nuclear fraction was extracted by using $50 \mu \mathrm{L}$ nuclear extraction buffer I. The remaining steps in the protocol were followed as described by the manufacturer. BCA assay was used to determine protein content.

\section{SDS-PAGE and Western blotting}

Equal amounts of proteins for each sample were denatured by addition of $2 \times$ Laemmli buffer (4\% SDS, $10 \%$ 2-mercaptoethanol, $20 \%$ glycerol, $0.004 \%$ bromophenol blue and $0.125 \mathrm{M}$ Tris- $\mathrm{HCl}$ ) and heated for $10 \mathrm{~min}$ at $98{ }^{\circ} \mathrm{C}$. Samples were separated on a $10 \%$ polyacrylamide gel and wet-transferred to polyvinylidene fluoride membrane $(1.5 \mathrm{~h}$ at $80 \mathrm{~V})$ or nitrocellulose (50 min at $80 \mathrm{~V}$ ). Membranes were blocked in $5 \%$ skimmed milk (in $\mathrm{PBS}^{-}{ }^{-}$) for $30 \mathrm{~min}$ prior to overnight incubation at $4{ }^{\circ} \mathrm{C}$ with the primary antibody in $5 \%$ skimmed milk. Membranes were washed with $0.1 \%$ Tween 20 in $\mathrm{PBS}^{-}{ }^{-}$and incubated for $1 \mathrm{~h}$ at room temperature with an HRPconjugated secondary antibody (1 : 10,000; Abcam; mouse: ab97040; rabbit: ab6721) in $5 \%$ skimmed milk (see Table 3 for list of primary antibodies and corresponding antibody concentrations). For cytoplasmic and nuclear fractions, EEA1 and fibrillarin were used as loading controls, respectively. Chemiluminescent signals were detected by addition of Amersham ECL Prime Western Blotting Detection
Reagent (GE Healthcare). Image J software was used to perform densitometry analysis. Densitometry values for the proteins of interest were normalised to the respective densitometry values for the appropriate loading control and expressed as a percentage of control.

\section{Quantification of PRG4 by ELISA}

PRG4 accumulation in cell culture medium was determined by indirect ELISA, as described previously (Schmidt et al., 2004). Briefly, culture medium samples were first adsorbed on to ELISA plates, then, following blocking, incubated with anti-PRG4 mAb 9G3 (2 $\mu \mathrm{g} / \mathrm{mL}$; MABT401, Millipore). Next, antimouse HRP-conjugated secondary antibody (125 ng/ $\mathrm{mL}$; A4416, Millipore), with washes in between, was applied. Finally, 3,3',5,5'-tetramethylbenzidine substrate was added, the reaction was stopped with $2 \mathrm{M} \mathrm{H}_{2} \mathrm{SO}_{4}$ and samples were read at $450 \mathrm{~nm}$ (SpectraMax i3 Multi-Mode microplate reader, Molecular Devices). Purified full-length recombinant human PRG4 standards (a generous gift from Lubris BioPharma LLC, Weston, MA, USA) were used to calculate PRG4 concentrations within the medium samples (Abubacker et al., 2015). Conditions were performed in triplicate and data were normalised to total DNA content.

\section{Immunofluorescence and confocal microscopy}

SZCs fixed in $4 \%$ paraformaldehyde were incubated for 30 min with $10 \%$ goat serum, $0.1 \%$ Triton X-100 in $\mathrm{PBS}^{-}{ }^{-}$. For G- and F-actin staining, samples were incubated for $1 \mathrm{~h}$ at room temperature with both Alexa Fluor 488 DNase I conjugate (1 : 500; D12371, Molecular Probes) and Alexa Fluor 598 phalloidin conjugate ( $1: 20$; A12380, Invitrogen) in $3 \%$ goat serum, $0.1 \%$ Triton $\mathrm{X}-100$ in $\mathrm{PBS}^{-}{ }^{-}$. For YAP/TAZ 
Table 3. List of primary antibodies and dilutions.

\begin{tabular}{|c|c|c|}
\hline Protein & Dilution & Manufacturer \\
\hline PRG4 & $1: 500$ & Millipore (MABT401) \\
\hline TNC & $1: 500$ & Abcam (ab108930) \\
\hline YAP/TAZ & $1: 500$ & Cell Signaling (8418S) \\
\hline Total actin & $1: 1,000$ & Millipore (MAB1501) \\
\hline GAPDH & $1: 3,000$ & Millipore (ABS16) \\
\hline EEA1 & $1: 1,000$ & BD Transduction Laboratories (610457) \\
\hline Fibrillarin & $1: 1,000$ & Cell Signaling (2639S) \\
\hline
\end{tabular}

Table 4. siRNA target sequences. * indicates a pool of 3 different siRNA duplexes.

\begin{tabular}{|c|c|c|c|c|}
\hline Target & \multicolumn{2}{|c|}{ Catalogue number } & Manufacturer & Target sequence \\
\hline Control & \multicolumn{2}{|c|}{ Sc-37007 } & $\begin{array}{c}\text { Santa Cruz } \\
\text { Biotechnology }\end{array}$ & Proprietary \\
\hline \multirow{3}{*}{ YAP } & \multirow{3}{*}{ Sc-38637* } & A & \multirow{3}{*}{$\begin{array}{c}\text { Santa Cruz } \\
\text { Biotechnology }\end{array}$} & $\begin{array}{c}\text { Sense: CCACCAAGCUAGAUAAAGAtt } \\
\text { Antisense: UCUUUAUCUAGCUUGGUGGtt }\end{array}$ \\
\hline & & B & & $\begin{array}{c}\text { Sense: GCAUGAGACAAUUUCCAUAtt } \\
\text { Antisense: UAUGGAAAUUGUCUCAUGCtt }\end{array}$ \\
\hline & & $\mathrm{C}$ & & $\begin{array}{l}\text { Sense: GGGUGUGCCUAUCAUAACAtt } \\
\text { Antisense: UGUUAUGAUAGGCACACCCtt }\end{array}$ \\
\hline \multirow{3}{*}{ TAZ } & \multirow{3}{*}{ Sc-270559* } & A & \multirow{3}{*}{$\begin{array}{c}\text { Santa Cruz } \\
\text { Biotechnology }\end{array}$} & $\begin{array}{c}\text { Sense: CUUCCUCAAUCACAUAGAAtt } \\
\text { Antisense: UUCUAUGUGAUUGAGGAAGtt }\end{array}$ \\
\hline & & B & & $\begin{array}{c}\text { Sense: CAUGAGAUCCAUCACUAAUtt } \\
\text { Antisense: AUUAGUGAUGGAUCUCAUGtt }\end{array}$ \\
\hline & & $\mathrm{C}$ & & $\begin{array}{c}\text { Sense: CUUGUGGCCAGGUUAAUAAtt } \\
\text { Antisense: UUAUUAACCUGGCCACAAGtt }\end{array}$ \\
\hline Control & \multicolumn{2}{|c|}{ D-001210-02-20 } & Dharmacon & UAAGGCUAUGAAGAGAUAC \\
\hline MRTF-A & \multicolumn{2}{|c|}{ Custom made } & Dharmacon & $\begin{array}{l}\text { Sense: CAGCACUACAACUACCAGAUU } \\
\text { Antisense: UCUGGUAGUUGUAGUGCUGUU }\end{array}$ \\
\hline
\end{tabular}

detection, samples were incubated overnight at $4{ }^{\circ} \mathrm{C}$ with an antibody against YAP/TAZ (1 : 250; 8418S, Cell Signaling) in $3 \%$ goat serum in $0.1 \%$ Triton $X-100$ in $\mathrm{PBS}^{-} /$. Samples were washed and incubated for $1 \mathrm{~h}$ at room temperature with the secondary antibody goat anti-rabbit IgG-conjugated Alexa Fluor ${ }^{\mathrm{TM}} 488$ (1 : 250; A11008, Invitrogen) and Alexa Fluor ${ }^{\mathrm{TM}} 598$ phalloidin-conjugated (1 : 20; A12380, Invitrogen) (to stain filamentous actin) in $3 \%$ goat serum, $0.1 \%$ Triton X-100 in $\mathrm{PBS}^{-} /$. For both G- and F-actin and YAP/TAZ staining, samples were counterstained for 5 min with DAPI $(1: 1,500)$. A NikonC1si laser scanning confocal microscope was used to acquire the confocal microscopy images. All images were taken in the same plane, where the nuclei diameter appeared the largest.

\section{Lipofectamine transfection}

After $24 \mathrm{~h}$ in monolayer culture, SZCs seeded on to a 6-well plate at $5.2 \times 10^{3}$ cells $/ \mathrm{cm}^{2}$ were incubated with $7.5 \mu \mathrm{L}$ Lipofectamine 3000 reagent (Invitrogen) and 100 pmol siRNA (Table 4) per well in DMEM supplemented with $1 \%$ ITS+, $100 \mathrm{nM}$ dexamethasone, $40 \mu \mathrm{g} / \mathrm{mL}$ proline, $100 \mathrm{mM}$ pyruvate and $100 \mu \mathrm{g} /$ $\mathrm{mL}$ ascorbic acid. Samples were harvested at time points ranging from $24 \mathrm{~h}$ to $5 \mathrm{~d}$ post transfection for analysis. For samples harvested on day 5, medium was changed on day 3.

\section{Statistical analysis}

Sufficient cell numbers for each independent experiment were obtained by pooling SZ cartilage from 6-9 joints. Each independent experiment was repeated 3-4 times. Gene expression (performed in triplicate) and densitometry data are expressed as mean \pm SD. Prism statistical analysis software was used to perform student's t-test (between two groups) or one-way analysis of variance with Tukey's post-hoc test ( $>$ two groups). Statistical significance was assigned at $p<0.05$. A Bonferonni's corrected $t$-test was used to assess statistical significance when comparing LatB and CytoD treatment groups to control. For this statistical test, the significance was adjusted to account for the multiple comparisons and assigned at $p<0.025$.

\section{Results}

\section{CDC42 inhibition reduced YAP/TAZ protein}

\section{levels and nuclear localisation of TAZ}

To determine the effect of pharmacological CDC42 inhibition on YAP/TAZ total levels and cytoplasmic/ nuclear localisation, SZCs were treated with the CDC42 chemical inhibitor ML141 (CDC42i). Although treatment with ML141 significantly increased $Y A P / T A Z$ mRNA levels to $275 \pm 61 \%$ 
(YAP) and $252 \pm 30 \%$ (TAZ) (Fig. 1a), total protein levels significantly decreased to $28 \pm 26 \%$ (YAP) and $21 \pm 10 \%$ (TAZ) as compared to control (Fig. 1b,c). In keeping with this, confocal imaging revealed less prominent YAP/TAZ staining throughout the cell with ML141 treatment (Fig. 1d). Nuclear and cytoplasmic extraction of cellular components indicated that YAP was predominantly localised in the cytoplasm, while TAZ was in both cytoplasmic and nuclear fractions (Fig. 1e). Treatment with ML141 resulted in a significant decrease in nuclear TAZ $(4 \pm 2 \%$ as compared to control) with no significant effect on cytoplasmic $Y A P(61 \pm 48 \%$ as compared to control) or TAZ (45 $\pm 33 \%$ as compared to control) (Fig. 1f,g). A decrease in YAP/TAZ downstream target gene CTGF was also observed $(42 \pm 17 \%$ as compared to control) (Fig. 1h). Nuclear YAP was only detectable for 1 of 3 sets; therefore, quantification of the nuclear portion of YAP was not performed.

\section{Non-canonical regulation of YAP/TAZ by the} actin cytoskeleton

Delve et al. (2018) demonstrated that CDC42 inhibition regulates actin polymerisation status resulting in an a

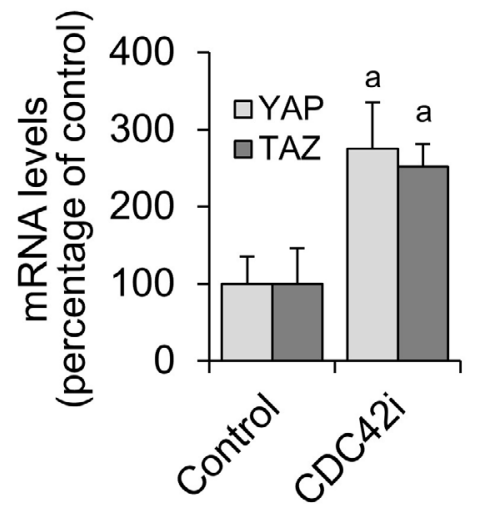

d
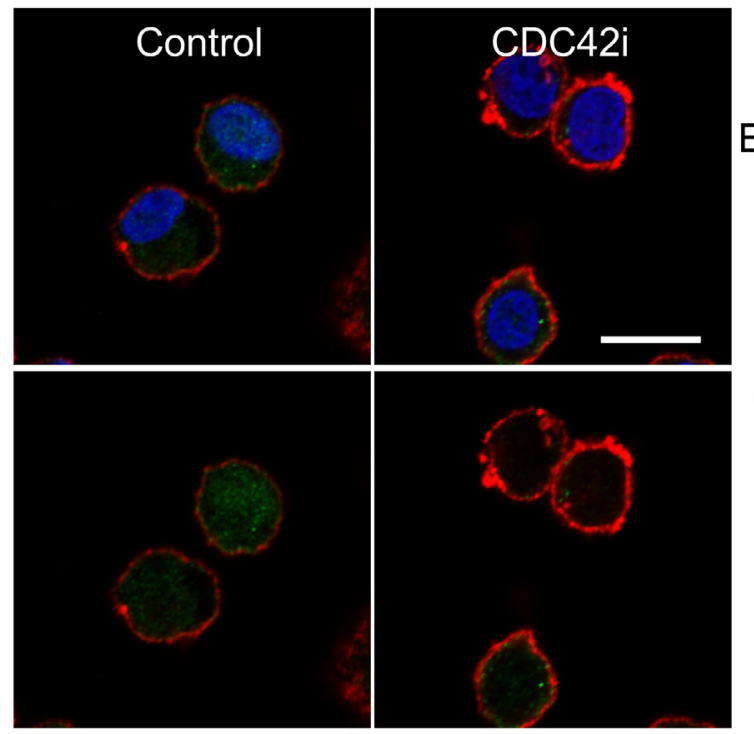

YAP/TAZ / F-Actin / Nucleus
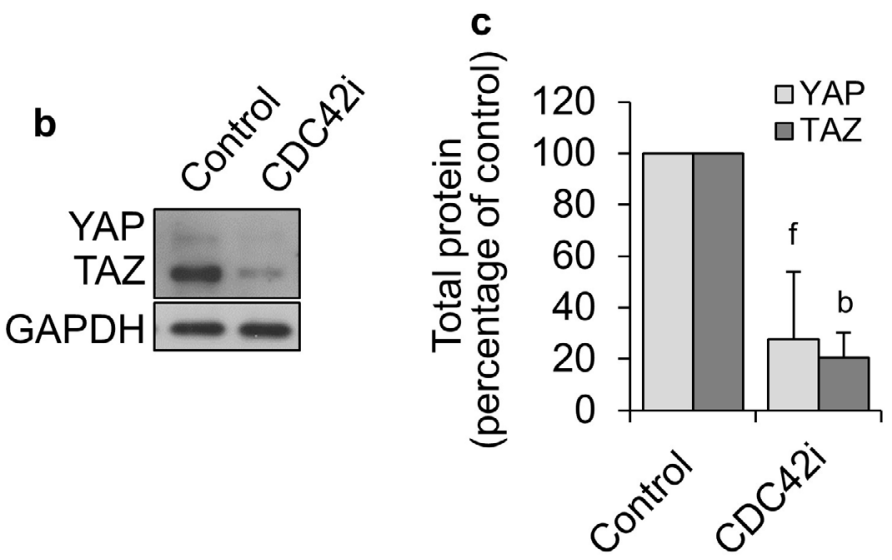

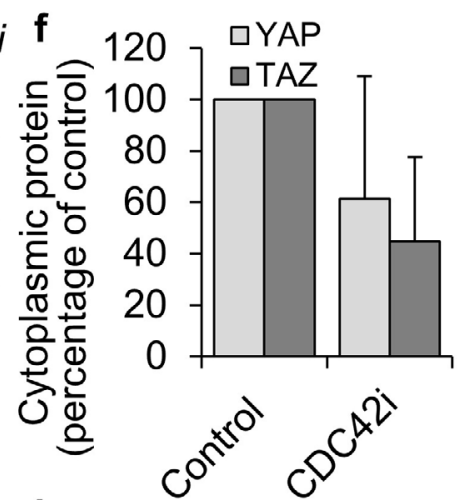

h
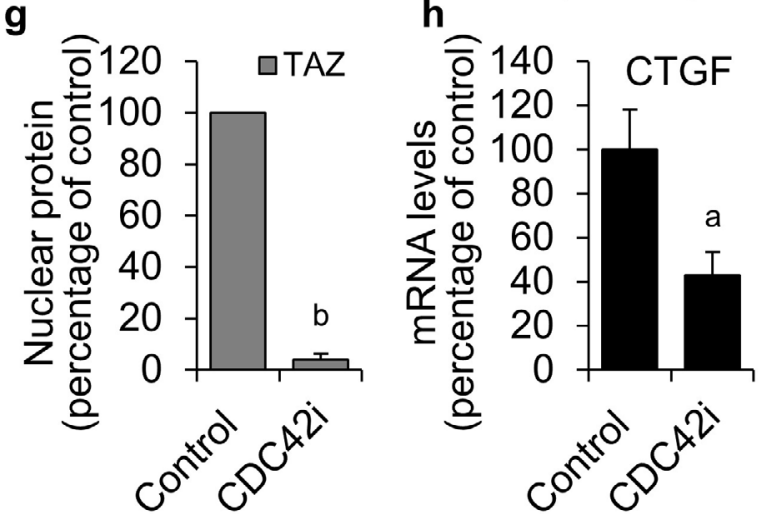

Fig. 1. The effect of inhibiting CDC42 with the chemical inhibitor ML141 on expression and localisation of YAP/TAZ. (a) YAP/TAZ expression. (b) YAP/TAZ total protein levels and corresponding (c) densitometry values. (d) Confocal imaging of YAP/TAZ distribution in the absence (control) and presence of ML141 $($ CDC42i); green $=$ YAP/TAZ; red $=$ filamentous actin; blue $=$ nucleus. Scale bar $=10 \mu \mathrm{m} .(\mathbf{e})$ Nuclear $(\mathrm{N}) /$ cytoplasmic (C) localisation of YAP/TAZ determined by Western blot and corresponding (f,g) densitometry values relative to EEA1 for cytoplasmic and fibrillarin (fib) for nuclear levels. (h) YAP/TAZ target gene, CTGF, mRNA levels. Analyses were performed after $24 \mathrm{~h}$ of treatment. Results are expressed as mean \pm SD. $n=3-4$. ${ }^{\mathrm{a}} p<0.0001 ;{ }^{\mathrm{b}} p<0.001 ;{ }^{\mathrm{f}} p<0.05$ as compared to control. 
increase in G-/F-actin ratio with ML141 treatment in SZCs. To determine whether actin polymerisation regulated YAP/TAZ localisation in SZCs, actin polymerisation was modulated by treatment with one of two chemical depolymerising agents (LatB and CytoD), which function through different mechanisms (Carlier et al., 1986; Yarmola et al., 2000). Treatment with LatB significantly decreased nuclear TAZ levels ( $41 \pm 12 \%$ as compared to control) whereas CytoD showed a trend towards increasing nuclear TAZ levels (267 $\pm 102 \%$ as compared to control). Cytoplasmic levels of YAP/TAZ were not significantly altered although there was a trend towards reduced cytoplasmic YAP with LatB treatment (55 $\pm 38 \%$ as compared to control). No significant change in cytoplasmic TAZ was observed (Fig. 2a-c). To confirm the effect of actin polymerisation on the regulation of YAP/TAZ, the effect of LatB and CytoD treatment on CTGF mRNA levels, a downstream target gene, was determined. There was a significant decrease with LatB treatment (37 $\pm 17 \%$ as compared to control) and a significant increase with CytoD treatment (172 $\pm 77 \%$ as compared to control) (Fig. 2 d), which corresponded to changes in nuclear TAZ levels.

a

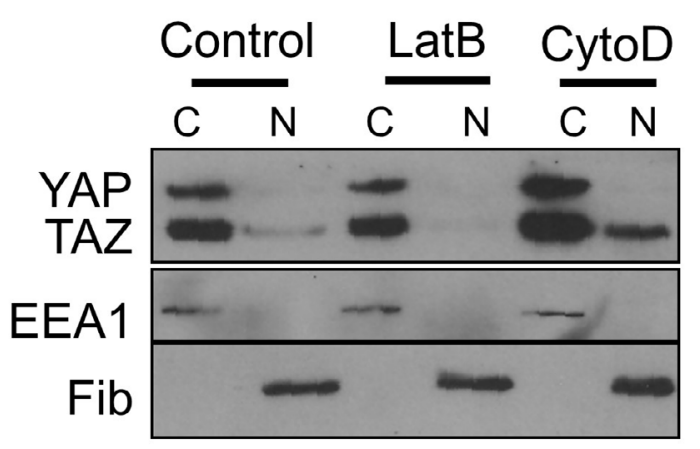

b

C
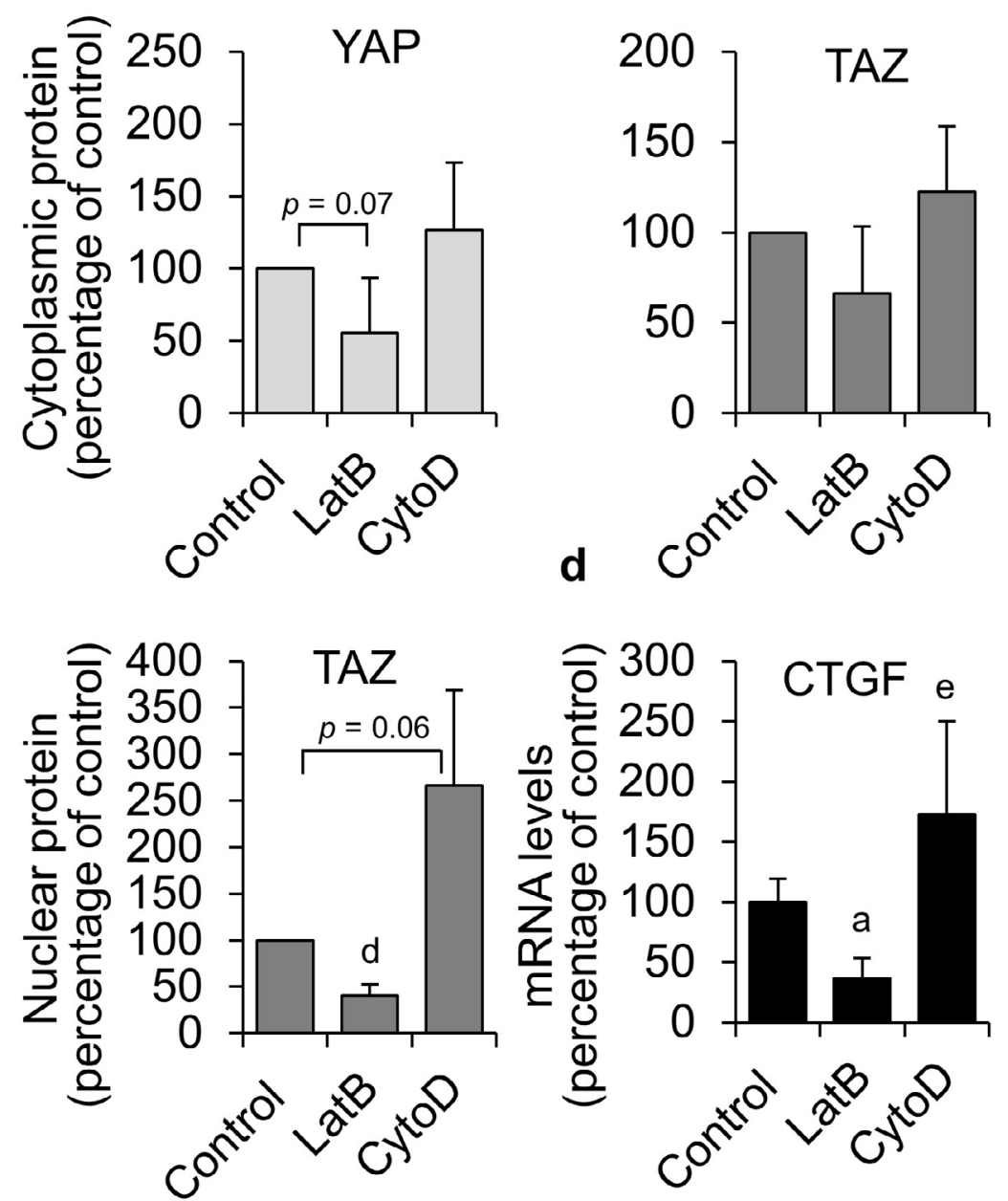

Fig. 2. Regulation of YAP/TAZ by the actin cytoskeleton in SZCs. (a) Nuclear (N)/cytoplasmic (C) localisation of YAP/TAZ determined by Western blot and corresponding densitometry values for (b) cytoplasmic and (c) nuclear YAP/TAZ levels. YAP nuclear levels were not measured as they were not detectable in most experiments. (d) YAP/TAZ target gene, CTGF, mRNA levels. Results are expressed as mean $\pm \mathrm{SD}$. Analyses were performed after $24 \mathrm{~h}$ of treatment. $n=4 .{ }^{\mathrm{a}} p<0.0001 ;{ }^{\mathrm{d}} p<0.005$; ${ }^{\mathrm{e}} p<0.01$ as compared to control. 
Depolymerisation of the actin cytoskeleton also affected total YAP/TAZ levels. Treatment with LatB significantly decreased total YAP and TAZ levels to $21 \pm 5 \%$ and $75 \pm 3 \%$ as compared to control, respectively, while CytoD increased YAP and TAZ levels to $146 \pm 85 \%$ and $121 \pm 12 \%$ as compared to control, respectively, although this effect was not statistically significant (Fig. 3).

\section{The effect of verteporfin on the SZ phenotype}

The effect of chemical inhibition of YAP/TAZ with verteporfin $(1 \mu \mathrm{M})$ on the $S Z$ phenotype was determined. To confirm effective inhibition, the downstream YAP/TAZ target gene expression at the selected dose of verteporfin $(1 \mu \mathrm{M})$ was determined. CTGF mRNA levels were significantly decreased after treatment ( $28 \pm 26 \%$ as compared to control) (data not shown). Decreases in PRG4 (16 $\pm 6 \%$ as compared to control) and TNC (15 $\pm 9 \%$ as compared to control) mRNA levels and PRG4 (35 $\pm 8 \%$ as compared to control) and TNC (43 $\pm 26 \%$ as compared to control) protein levels were observed after chemical inhibition of YAP/TAZ (Fig. 4a-f). There were no observable changes in the actin cytoskeleton arrangement as observed by confocal microscopy (Fig. 4g) or change in the polymerisation status of the actin cytoskeleton, as determined by G-/F-actin ratio (Fig. 4h). Treatment with verteporfin had no effect on total actin levels (Fig. 4i).

\section{YAP and TAZ did not have compensatory roles in} SZCs

To investigate the roles of YAP/TAZ in the regulation of the SZ phenotype, YAP and TAZ were knocked down with siRNA independently and in combination. A time-course study showed that TAZ knockdown by siRNA was maximal at $1 \mathrm{~d}$ (data not shown) and this time point was used for subsequent gene expression studies. Protein evaluation at 2 and $3 \mathrm{~d}$ following transfection with TAZ siRNA indicated that $3 \mathrm{~d}$ was the optimal time point that was used for subsequent studies (data not shown). Protein levels were decreased for YAP (siY: $17 \pm 12 \%$ as compared to control; siYT: $22 \pm 16 \%$ as compared to control) and TAZ (siT: $51 \pm 8 \%$ as compared to control; siYT: $53 \pm 30 \%$ as compared to control) at $3 \mathrm{~d}$. Knockdown of YAP (siY) did not affect TAZ ( $88 \pm 8 \%$ as compared to control) protein levels and, similarly, knockdown of TAZ (siT) did not affect YAP $(89 \pm 27 \%$ as compared to control) protein levels (Fig. 5a,b).

\section{PRG4 and TNC were regulated by YAP/TAZ}

The role of YAP/TAZ in the regulation of the SZ phenotype was further investigated by siRNAmediated knockdown, as chemical agents may have off-target effects. YAP and TAZ knockdown was performed individually and in combination and the effect on PRG4 and TNC expression was determined. PRG4 mRNA levels were significantly decreased with YAP (siY; $68 \pm 26 \%$ as compared to control) and TAZ (siT; $54 \pm 21 \%$ as compared to control) knockdown independently and in combination (siY/T; $61 \pm 29 \%$ as compared to control) (Fig. 5c). PRG4 protein levels were determined by ELISA and, although no significant differences were observed at $3 \mathrm{~d}$ (data not shown), significant decreases from control levels

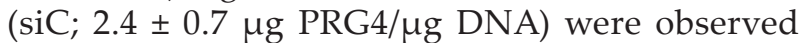

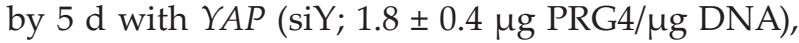

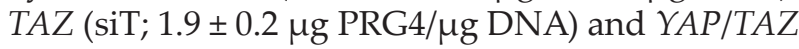

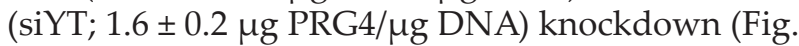
5d). TNC mRNA levels were significantly decreased with TAZ knockdown independently (siT; $67 \pm 18 \%$ as compared to control) and in combination with YAP (siY/T; $66 \pm 35 \%$ as compared to control), with no significant effect observed with YAP knockdown (siY; $84 \pm 33 \%$ as compared to control) (Fig. 5e). Similarly, TNC protein levels significantly decreased with TAZ knockdown independently (siT; $50 \pm 18 \%$ as compared to control) and in combination with YAP (siY/T; $49 \pm 21 \%$ as compared to control), with no significant effect observed with $Y A P$ knockdown (siY; $82 \pm 20 \%$ as compared to control) (Fig. 5f,g). No
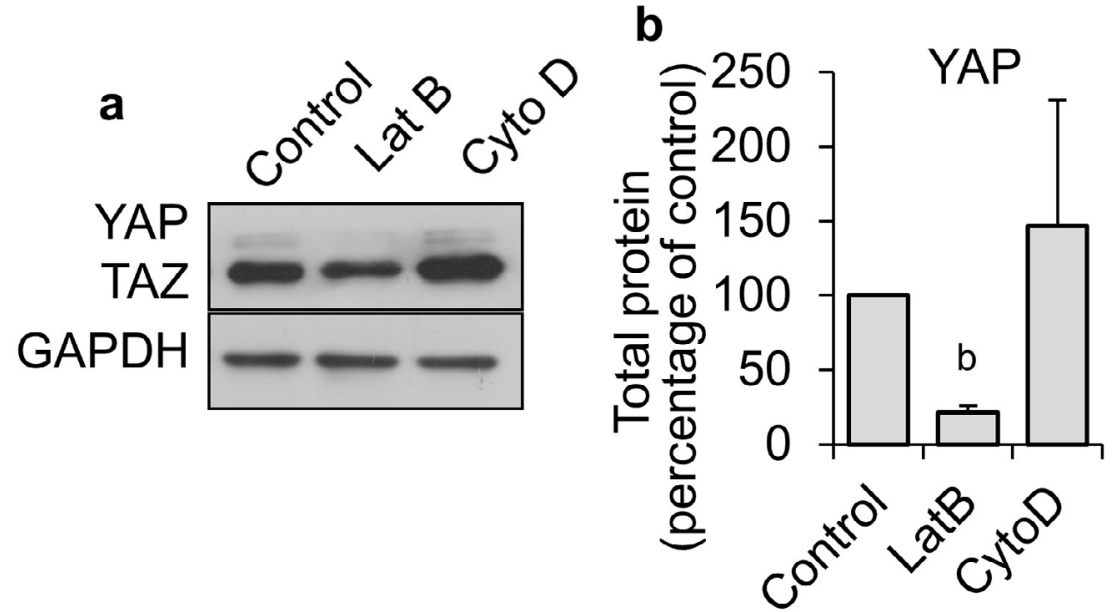

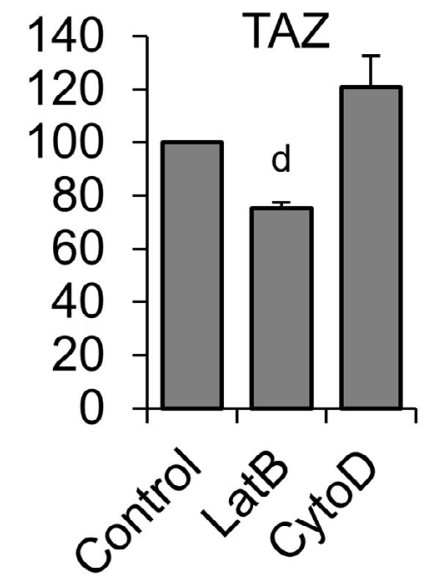

Fig. 3. Regulation of total YAP/TAZ protein levels by the actin cytoskeleton in SZCs. (a) Western blot showing total YAP/TAZ protein levels and (b) densitometry values. Analyses were performed after $24 \mathrm{~h}$ of treatment. Results are expressed as mean \pm SD. $n=3 .{ }^{\mathrm{b}} p<0.001 ;{ }^{\mathrm{d}} p<0.005$ as compared to control. 

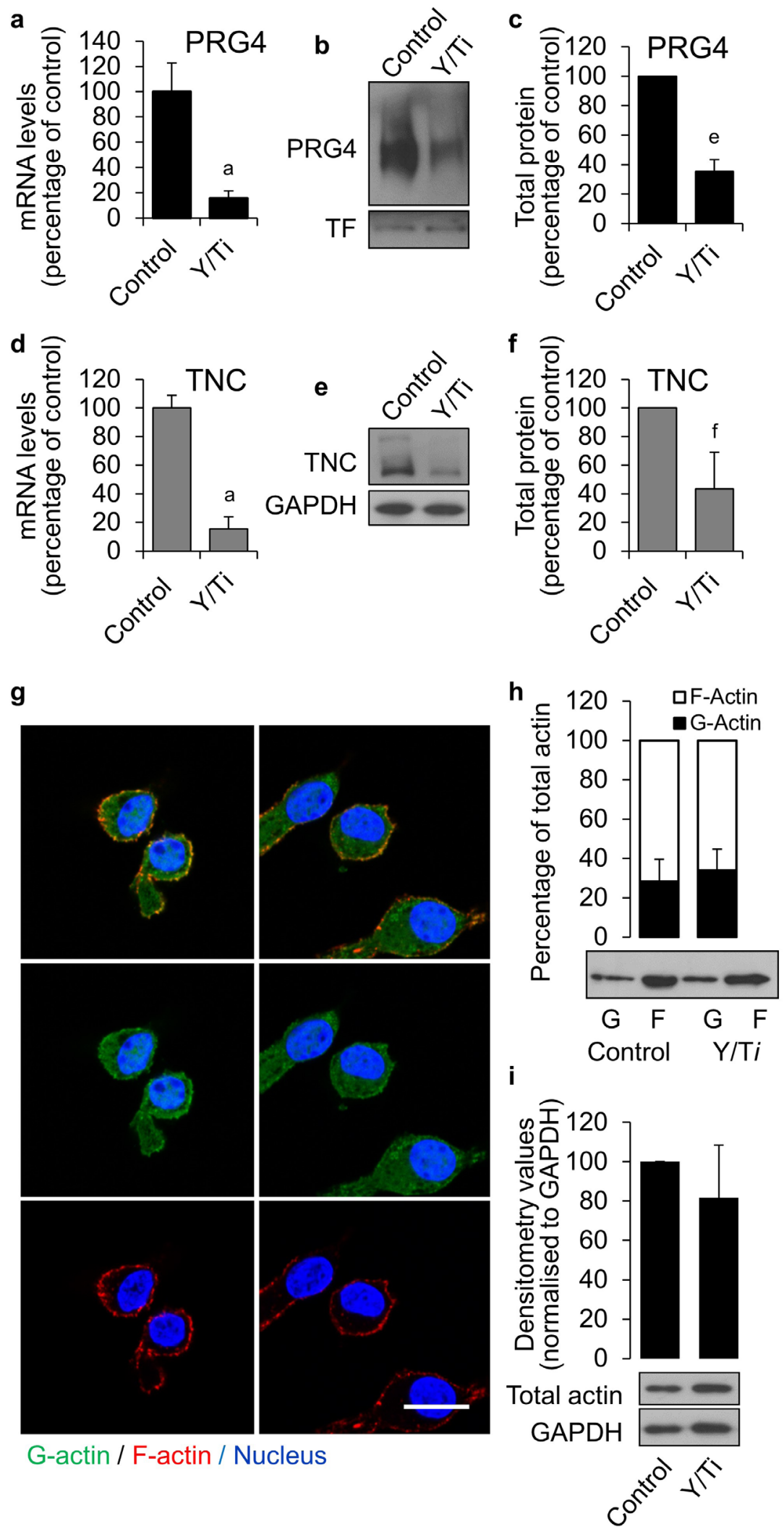

Fig. 4. Chemical inhibition of YAP/TAZ inhibited PRG4 and TNC expression. SZCs were cultured in the absence (control) or presence of verteporfin (Y/Ti) for $24 \mathrm{~h}$ and the effect on PRG4 and TNC expression and actin polymerisation was determined. (a) Effect of verteporfin on PRG4 expression. (b) Secreted protein levels and corresponding (c) densitometry analysis of PRG4 secreted protein. TF = transferrin (loading control). (d) Effect of verteporfin on TNC expression. (e) TNC protein levels and corresponding (f) densitometry analysis of TNC protein. (g) Effect of verteporfin on actin status determined by confocal imaging of actin organisation; green = globular actin; red = filamentous actin; blue = nucleus. Scale bar $=10 \mu \mathrm{m}$. (h) G-/F-actin ratio determined by Western blot and densitometry analysis. (i) Total actin as determined by Western blot and densitometry. Results are expressed as mean \pm SD. $n=3-4 .{ }^{a} p<0.0001$; ${ }^{\mathrm{e}} p<0.01 ;{ }^{\mathrm{f}} p<0.05$ as compared to control. 
synergistic effect on PRG4 or TNC expression was observed when YAP and TAZ were knocked down in combination.

TAZ localisation was regulated by MRTF-A in SZCs In SZCs, a trend towards increased YAP/TAZ expression was observed with CytoD treatment, which can activate MRTF-A signalling, suggesting a regulation of YAP/TAZ by MRTF-A (Parreno et al., 2016). As TNC expression is regulated by MRTF-A downstream of CDC42 and actin polymerisation in SZCs (Delve et al., 2018), the regulation of YAP/ TAZ by MRTF-A was investigated. To investigate the intersection of these pathways, siRNA-mediated knockdown of MRTF-A was performed and the effect on YAP/TAZ expression and localisation was determined. MRTF-A expression is significantly reduced by $3 \mathrm{~d}$ (Delve et al., 2018), therefore this time point was decided upon. MRTF- $A$ knockdown did not significantly change YAP mRNA levels at $3 \mathrm{~d}$ (74 $\pm 18 \%$ as compared to control) or at $5 \mathrm{~d}(103 \pm 73 \%$ as compared to control); however, decreased TAZ expression was observed at $3 \mathrm{~d}(64 \pm 23 \%$ as compared to control) (Fig. 6a). Total protein levels remained unchanged at $3 \mathrm{~d}$ (YAP: $120 \pm 99 \%$ as compared to control; TAZ: $82 \pm 28 \%$ as compared to control) and $5 \mathrm{~d}$ (YAP: $76 \pm 30 \%$ as compared to control; TAZ: $91 \pm 45 \%$ as compared to control) (Fig. $6 \mathbf{b}, \mathbf{c})$. To determine whether MRTF-A influenced nuclear translocation of YAP/TAZ, cytoplasmic and nuclear fractions were extracted (Fig. 6d). By $5 \mathrm{~d}$, a significant decrease in nuclear TAZ $(60 \pm 16 \%$ as compared to control) was observed with MRTF-A knockdown (Fig. 6f). a

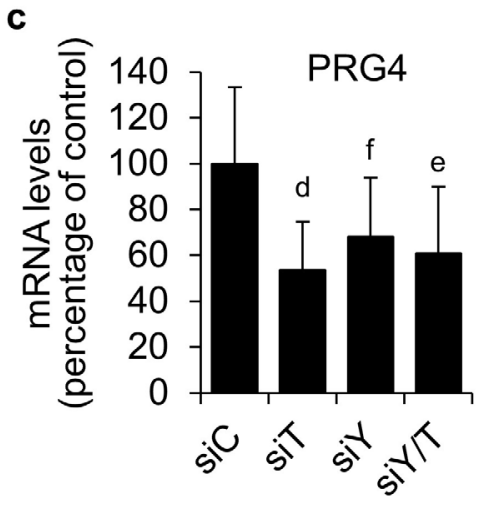

b
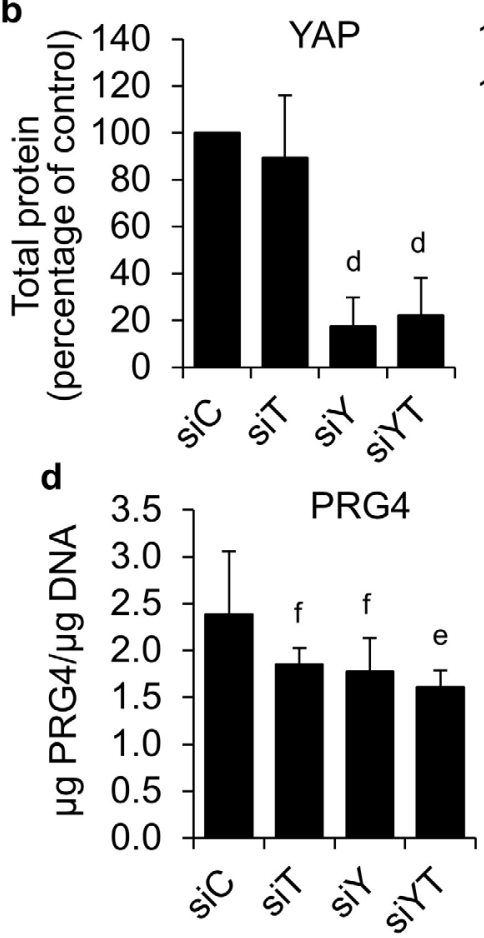

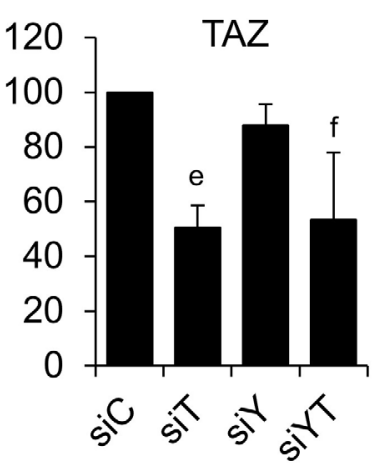

e
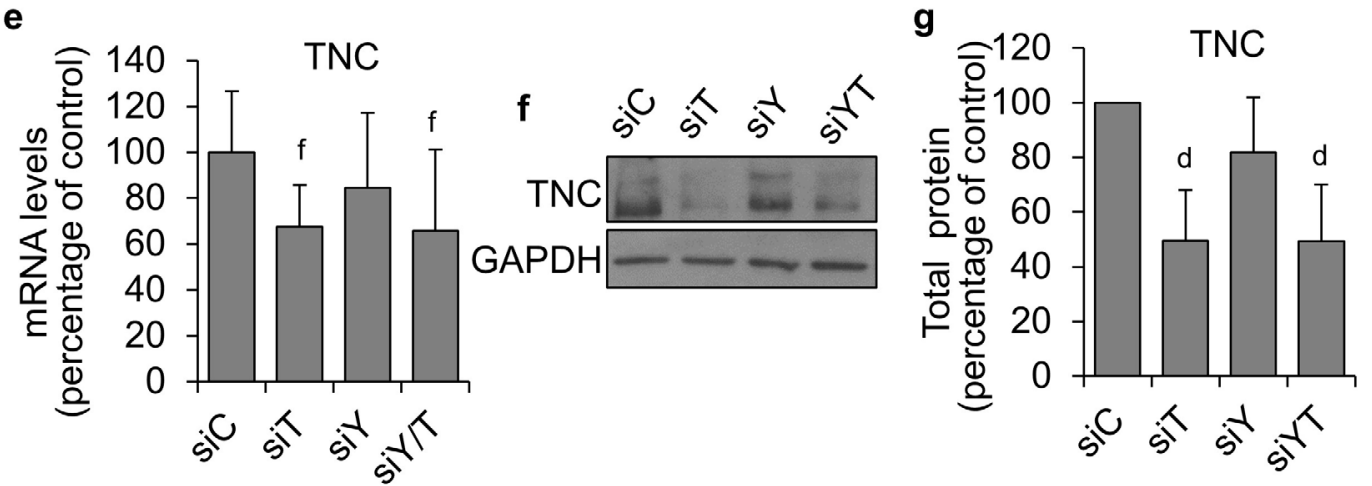

Fig. 5. YAP/TAZ regulated SZC phenotype. Treating SZC s with siTAZ (siT), siYAP (siY) or siYAP and siTAZ (siYT) together was effective in knocking down YAP and TAZ protein as determined by (a) Western blot and (b) densitometry quantification. Effect of YAP/TAZ knockdown on (c) PRG4 mRNA levels at $24 \mathrm{~h}$ and (d) secreted PRG4 protein levels determined by ELISA at $5 \mathrm{~d}$. (e) TNC mRNA levels at $24 \mathrm{~h}$ and (f) TNC protein levels at $3 \mathrm{~d}$ as determined by Western blotting and (g) densitometry analysis. Results are expressed as mean \pm SD. $n=3-4 .{ }^{\mathrm{d}} p<0.005 ;{ }^{\mathrm{e}} p<0.01 ;{ }^{\mathrm{f}} p<0.05$ as compared to control. siC: control siRNA. 


\section{Discussion}

The present study further elucidated the signalling pathways linking CDC42 and actin polymerisation status in the regulation of PRG4 and TNC in SZCs through YAP/TAZ. Actin status influenced TAZ nuclear localisation as treatment with the actin depolymerisation agent LatB led to both decreased levels and nuclear localisation of TAZ. Chemical inhibition of YAP/TAZ by verteporfin resulted in decreased PRG4 and TNC levels. This effect was confirmed by siRNA knockdown of TAZ, which resulted in significantly decreased levels of PRG4 and TNC. This effect was not further increased by knockdown of both YAP and TAZ. Interestingly knockdown of $Y A P$ had no effect on TNC gene and protein expression levels but did decrease PRG4 levels. Treatment with the actin depolymerising agent CytoD led to increased nuclear TAZ $(p=0.06)$, leading to the investigation of TAZ regulation by MRTF-A. Although total TAZ levels were not affected by $M R T F-A$ knockdown, decreases in nuclear TAZ were observed at $5 \mathrm{~d}$. To the best of the authors knowledge, this was the first report demonstrating the regulation of PRG4 and TNC by YAP/TAZ in SZCs.

Regulation of YAP/TAZ by CDC42 was demonstrated by chemical inhibition with ML141 treatment, as it resulted in reduced total YAP/
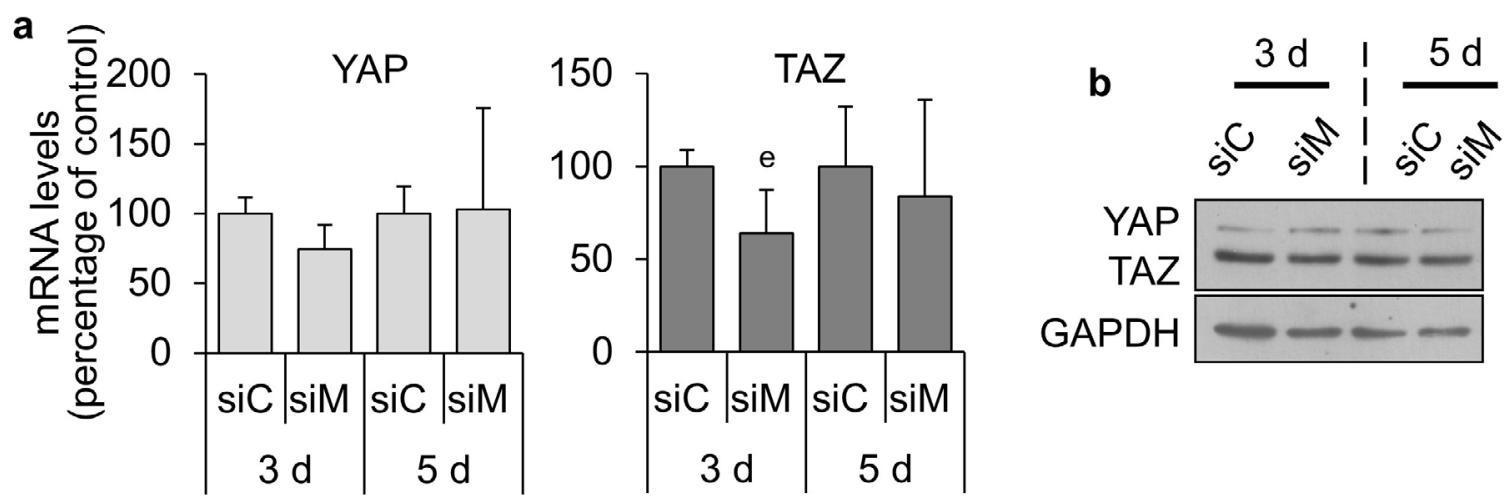

C
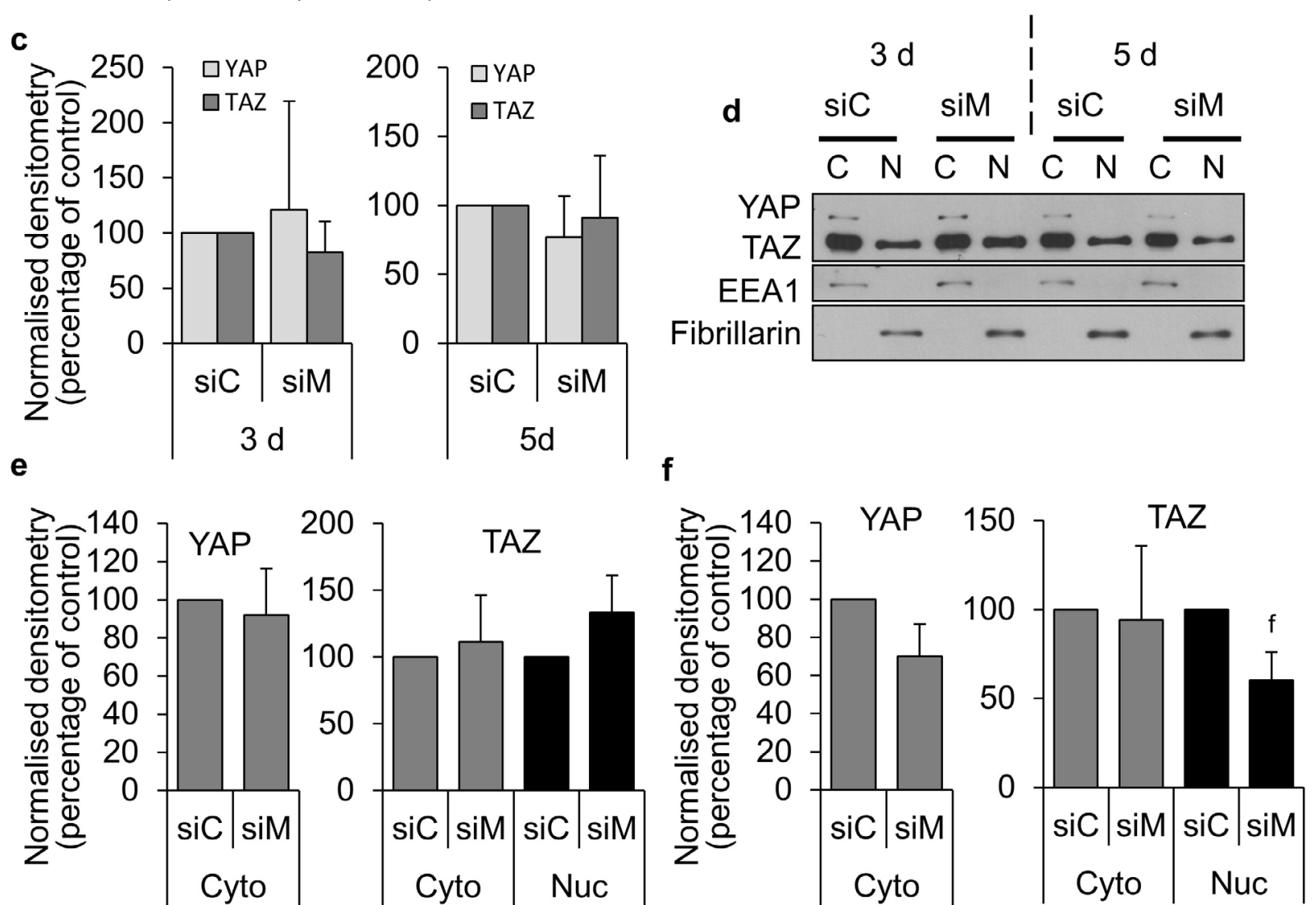

Fig. 6. Effect of MRTF-A knockdown on YAP/TAZ. MRTF- $A$ was knocked down in SZCs and the effect on (a) YAP/TAZ mRNA and (b) total protein levels was determined. (c) Densitometry quantification of YAP/TAZ total protein. (d) Effect on YAP/TAZ cytoplasmic/nuclear localisation by Western blot. The corresponding densitometry values relative to EEA1 for cytoplasmic and fibrillarin for nuclear levels are presented at (e) $3 \mathrm{~d}$ and (f) $5 \mathrm{~d}$. Results are expressed as mean $\pm \mathrm{SD} . n=3$. ${ }^{\mathrm{e}} p<0.01 ;{ }^{\mathrm{f}} p<0.05$ as compared to control. siC: control siRNA. siM: MRTF-A siRNA. 
TAZ protein levels and nuclear TAZ levels and decreased YAP/TAZ target gene (CTGF) expression. Downstream of CDC42, the involvement of a non-canonical pathway in the regulation of YAP/ TAZ was demonstrated by treating SZCs with two chemical actin-depolymerising agents that have different mechanisms of action. LatB treatment decreased while CytoD increased YAP/TAZ total levels and nuclear TAZ. This correlated with a significant decrease and increase in CTGF mRNA levels with LatB and CytoD treatment, respectively. Regulation of YAP/TAZ by CDC42 inhibition and actin depolymerisation (LatB treatment) in SZCs was consistent with previously published reports in other cell types. In a study of nephrogenesis, a conditional knockout of $Y A P$ resulted in the reduction of nuclear YAP and YAP-dependent gene expression and this was reproduced by deletion of CDC42 (Reginensi et al., 2013). Additionally, decreased nuclear YAP/ TAZ levels with LatB treatment has been observed in different cells types, including embryonic fibroblasts (NIH3T3 cells) (Wada et al., 2011), HeLa cells (Foster et al., 2012), trabecular meshwork cells (Thomasy et al., 2013), vascular smooth muscle cells (Kimura et al., 2016) and epidermal stem cells (Totaro et al., 2017). Although LatB treatment reduces nuclear YAP/TAZ levels in a variety of cell types, treatment with LatB can also lead to YAP phosphorylation on serine residue 397, leading to protein degradation, in addition to serine 127 (cytoplasmic sequestration), suggesting LatB may also affect total YAP levels (He et al., 2016; Kimura et al., 2016). Regulation of YAP/ TAZ by actin polymerisation is a well-characterised phenomenon; however, the regulation of the SZ phenotype by actin polymerisation has only been partly elucidated. The present study furthers the understanding of how actin polymerisation regulates the SZ phenotype and demonstrated a novel finding linking actin polymerisation to the regulation of PRG4 and TNC through YAP/TAZ.

The study showed that SZCs predominantly expressed TAZ. While TAZ was detectable in both nuclear and cytoplasmic fractions, YAP was only detected in the cytoplasmic fraction. Intriguingly, even though increases in YAP/TAZ expression were observed with CytoD treatment, YAP remained undetectable in the nuclear fraction. YAP and TAZ share approximately $60 \%$ protein sequence homology and have demonstrated redundant functional roles; however, YAP and TAZ also can function independently (Plouffe et al., 2018). First, the residues required for YAP and TAZ interaction with TEAD are conserved, but TAZ forms a heterotetrametric complex that affects DNA binding and more strongly induces target-gene expression (Kaan et al., 2017). Second, YAP is involved in mRNA processing through two domains not present in TAZ (an SH3binding motif and an N-terminal proline-rich region) (Plouffe et al., 2018). Third, TAZ contains a unique phosphodegron that is directly phosphorylated by
GSK3 (Huang et al., 2012). Despite these structural differences, YAP/TAZ have compensatory roles in many cell types (Finch-Edmondson et al., 2015). However, the data presented raise the possibility that YAP and TAZ function independently in SZCs. Treatment with YAP/TAZ chemical inhibitor verteporfin resulted in decreases in PRG4 and TNC gene and protein levels. This observation was confirmed using siRNA-mediated knockdown of YAP and TAZ. Decreased PRG4 expression was observed with YAP/TAZ knockdown and decreased TNC expression with TAZ knockdown. Although TAZ knockdown resulted in a reduction of protein levels to roughly $50 \%$ of the control, this was sufficient to reduce the expression of PRG4 and TNC. The reduction in PRG4 and TNC mRNA levels were $54 \pm 21 \%$ and $67 \pm 18 \%$ as compared to control, respectively, which may reflect TAZ knockdown efficiency. YAP/TAZ target genes include numerous proteins involved in regulating cell morphology and cytoskeletal organisation (Moya and Halder, 2018); however, no changes were observed in cell morphology or actin organisation with verteporfin treatment. This analysis was performed at $24 \mathrm{~h}$ and it is possible that a longer time in culture is required to observe differences.

The increase in nuclear TAZ with CytoD treatment, albeit not significant, was unexpected as it has been shown to decrease nuclear YAP/TAZ in mouse embryonic fibroblasts (Wada et al., 2011) and epidermal stem cells (Totaro et al., 2017). This finding led to the investigation of the regulation of YAP/TAZ by MRTF-A in SZCs (Wada et al., 2011). siRNA-mediated knockdown of MRTF-A resulted in decreases in TAZ mRNA and nuclear TAZ protein levels with no change in YAP mRNA levels or cytoplasmic protein levels for TAZ or YAP. This is consistent with a previously published report in breast cancer cells showing that MRTF-A knockdown promotes TAZ cytosolic localisation, with no effect on YAP; however, this study also observed a decrease in TAZ expression (Speight et al., 2016). It is unclear whether TNC is regulated by TAZ indirectly through MRTF-A or whether TNC is regulated by TAZ and MRTF-A independently. In the present study, treatment with CytoD resulted in increased nuclear TAZ. This result was unexpected as PRG4 accumulation has been shown to decrease with CytoD treatment (Delve et al., 2018; McNary et al., 2014). CytoD has numerous off-target effects and it may be that other signalling pathways are involved in regulating PRG4 expression in addition to YAP/ TAZ (Ailenberg and Silverman, 2003; Medjkane et al., 2009). To confirm the role of the actin cytoskeleton in the regulation of PRG4, the actin cytoskeleton was modulated by siRNA-mediated knockdown of cofilin, which has been shown to increase actin polymerisation in passaged chondrocytes (Parreno et al., 2017). In preliminary experiments, cofilin knockdown resulted in increased expression of PRG4, 
supporting a role for actin status (polymerisation) in the regulation of PRG4. Increases were also observed for TNC mRNA levels (data not shown).

While only TAZ regulated expression of TNC, both YAP and TAZ regulated expression of PRG4. In the present system, SZCs expressed more TAZ protein, which was detected in the nucleus and cytoplasm, while YAP was predominantly detected in the cytoplasmic fraction. Despite this, knockdown of YAP resulted in inhibition of PRG4 mRNA and secreted protein levels, even though YAP was not detectable in the nuclear fraction. There are several possibilities to explain this finding. First, this could suggest that the levels of YAP were too low to be detected in the nuclear fraction by the methodology used in the present study but that small undetectable changes in nuclear protein were sufficient to affect PRG4 expression. Second, since YAP is primarily located in the cytoplasm, YAP knockdown likely decreased cytoplasmic YAP suggesting a potential role in the regulation of PRG4 expression by intersection with another signalling pathway in the cytoplasm. Finally, CDC42 might regulate PRG4 expression through TAZ and the regulation of PRG4 through YAP that was observed with YAP knockdown might be occurring through a different mechanism. YAP/TAZ have been shown to intersect with known regulators of PRG4 expression, TGF- $\beta$ signalling and $\mathrm{Wnt} / \beta$-catenin signalling (Piersma et al., 2015). Phosphorylated YAP/TAZ inhibits TGF- $\beta$ signalling pathway by retaining Smads in the cytoplasm (Charbonney et al., 2011; Varelas et al., 2010). Although the mechanism regulating PRG4 expression through TGF- $\beta$ has not been fully elucidated, over-expression of Smad3 increases PRG4 expression in bovine chondrocytes (Chavez et al., 2017). It is possible that cytoplasmic localisation of YAP/TAZ in this system may result in decreased PRG4 expression by the cytoplasmic sequestration of Smad3.

A study conducted by McNary et al. (2014) demonstrated that TGF- $\beta 1$-induced PRG4 accumulation is not only modulated by CDC42 but also by other members of the Rho GTPase family, Rac1 and ROCK. While the focus of the present study and that of Delve et al. (2018) was to understand the regulation of the SZ phenotype by CDC42 and actin polymerisation, as elevated levels of molecules involved in CDC42 signalling are found in the SZ (Grogan et al., 2013), other members of the Rho GTPase family may also be contributing to the regulation of the SZ phenotype. For example, the Rho GTPase ROCK regulates cell contraction through the actin-myosin cytoskeleton (Amano et al., 2010). The role of cell contraction and actin-myosin cytoskeleton was not investigated in the present study; however, Dupont et al. (2011) showed that treatment with the ROCK inhibitor Y27632 or myosin inhibitor blebbistatin prevents nuclear accumulation of YAP/TAZ. Similar results were observed in a study conducted using cancer-associated fibroblasts by Calvo et al. (2013) as there was decreased nuclear
YAP and YAP-associated target gene expression with Y27632 or blebbistatin treatment.

Of note, treatment with the CDC42 inhibitor ML141 reduced total YAP/TAZ protein levels, despite up-regulation of $Y A P / T A Z$ mRNA levels, suggesting that inhibition of CDC42 may regulate pathway(s) involved in YAP/TAZ degradation. Although the mechanisms regulating YAP/TAZ degradation in chondrocytes have not been elucidated, CDC42 has been shown to inhibit GSK3 $\beta$ during wound healing and may be regulating pathways involved in ubiquitination and degradation of YAP/TAZ in SZCs (Etienne-Manneville and Hall, 2003). Additionally, loss of PRG4 in the temporomandibular joint of mice results in a decrease in condylar superficial $\mathrm{TNC}^{+}$cells by 1 month of age (Koyama et al., 2014). Although not studied in articular cartilage, this result might suggest that decreased PRG4 in SZCs may contribute to the loss of TNC expression. Further studies are required to investigate whether this was occurring in the present study.

\section{Conclusion}

The present study further elucidated the regulation of the SZ phenotype by the actin cytoskeleton and demonstrated the novel finding that YAP/TAZ regulated PRG4 and TNC expression and protein levels in SZCs. While TNC was regulated by TAZ, YAP and TAZ both regulated PRG4. It has yet to be determined whether YAP regulated PRG4 directly or indirectly by intersection with other known regulators of PRG4 and whether TNC was regulated by MRTF-A through TAZ or by both MRTF-A and TAZ independently. Understanding the mechanisms regulating PRG4 and TNC expression in vitro highlights the differential regulation of the primary SZ phenotype, which has cytoplasmic filamentous actin - as compared to chondrocytes isolated from full-thickness cartilage, which show a cortical distribution of actin - to promote the primary chondrocyte phenotype. The SZ is an important component of native cartilage that allows for smooth articulation of the joint and provides the tissue with the ability to withstand tensile forces (Hosseini et al., 2014; Rhee et al., 2005). While the focus of many cartilage-tissue engineering strategies is to recapitulate the bulk matrix properties of the native tissue, recapitulating the native tissue architecture requires the formation of the SZ. Understanding the molecular mechanisms regulating PRG4 and TNC expression furthers the understanding of how to possibly increase the expression of these chondroprotective molecules potentially by using culture methods to promote actin polymerisation and activation of YAP/TAZ in the SZ with the goal of forming and/or maintaining a functional SZ to improve the quality of tissue engineered cartilage constructs in vitro. 


\section{Acknowledgements}

The study was funded by the Canadian Institutes of Heath Research (CIHR) Grant \#MOP12611. ED was supported by the QEII-GSST Mount Sinai Scholarship in Science and Technology, Barbara and Frank Milligan Graduate Fellowship and the Samuel Lunenfeld Research Institute OSOTF Award. The purified recombinant human PRG4 was gifted generously from Lubris BioPharma LLC (Weston, MA, USA). TAS holds patents on recombinant human PRG4 and is a paid consultant for and holds equity in Lubris BioPharma LLC.

\section{References}

Abubacker S, Dorosz SG, Ponjevic D, Jay GD, Matyas JR, Schmidt TA (2015) Full-length recombinant human proteoglycan 4 interacts with hyaluronan to provide cartilage boundary lubrication. Ann Biomed Eng 44: 1128-1137.

Ailenberg M, Silverman M (2003) Cytochalasin D disruption of actin filaments in 3T3 cells produces an anti-apoptotic response by activating gelatinase A extracellularly and initiating intracellular survival signals. Biochim Biophys Acta 1593: 249-258.

Amano M, Nakayama M, Kaibuchi K (2010) Rhokinase/ROCK: a key regulator of the cytoskeleton and cell polarity. Cytoskeleton 67: 545-554.

Aragona M, Panciera T, Manfrin A, Giulitti S, Michielin F, Elvassore N, Dupont S, Piccolo S (2013) A mechanical checkpoint controls multicellular growth through YAP/TAZ regulation by actin-processing factors. Cell 154: 1047-1059.

Aydelotte MB, Kuettner KE (1988) Differences between sub-populations of cultured bovine articular chondrocytes. I. Morphology and cartilage matrix production. Connect Tissue Res 18: 205-222.

Benya PD, Shaffer JD (1982) Dedifferentiated chondrocytes reexpress the differentiated collagen phenotype when cultured in agarose gels. Cell 30: 215-224.

Brighton CT, Kitajima T, Hunt RM (1984) Zonal analysis of cytoplasmic components of articular cartilage chondrocytes. Arthritis Rheum 27: 12901299.

Calvo F, Ege N, Grande-Garcia A, Hooper S, Jenkins RP, Chaudhry SI, Harrington K, Williamson P, Moeendarbary E, Charras G, Sahai E (2013) Mechanotransduction and YAP-dependent matrix remodelling is required for the generation and maintenance of cancer-associated fibroblasts. Nat Cell Biol 15: 637-646.

Carlier M-F, Criquet P, Pantalon D, Korn ED (1986) Interaction of cytochalasin $\mathrm{D}$ with actin filaments in the presence of ADP and ATP. J Biol Chem 261: 20412050.

Chan B, Parreno J, Glogauer M, Wang Y, Kandel R (2019) Adseverin, an actin binding protein, regulates articular chondrocyte phenotype. J Tissue Eng Regen Med 13: 1438-1452.

Charbonney E, Speight P, Masszi A, Nakano H, Kapus A (2011) B-Catenin and Smad3 regulate the activity and stability of myocardin-related transcription factor during epithelial-myofibroblast transition. Mol Biol Cell 22: 4472-4485.

Chavez RD, Coricor G, Perez J, Seo HS, Serra $R$ (2017) SOX9 protein is stabilized by TGF- $\beta$ and regulates PAPSS2 mRNA expression in chondrocytes. Osteoarthritis Cartilage 25: 332-340.

Coles JM, Zhang L, Blum JJ, Warman ML, Jay GD, Guilak F, Zauscher S (2010) Loss of cartilage structure, stiffness, and frictional properties in mice lacking PRG4. Arthritis Rheum 62: 1666-1674.

Darling EM, Athanasiou KA (2006) Rapid phenotypic changes in passaged articular chondrocyte subpopulations. J Orthop Res 23: 425-432.

Decker RS, Um H-B, Dyment NA, Cottingham N, Usami Y, Enomoto-Iwamoto M, Kronenberg MS, Maye P, Rowe DW, Koyama E, Pacifici M (2017) Cell origin, volume and arrangement are drivers of articular cartilage formation, morphogenesis and response to injury in mouse limbs. Dev Biol 426: 5668.

Delve E, Parreno J, Co V, Wu P-H, Chong J, Di Scipio M, Kandel RA (2018) CDC42 regulates the expression of superficial zone molecules in part through the actin cytoskeleton and myocardinrelated transcription factor-A. J Orthop Res 36: 24212430.

Dupont S, Morsut L, Aragona M, Enzo E, Giulitti S, Cordenonsi M, Zanconato F, Le Digabel J, Forcato M, Bicciato S, Elvassore N, Piccolo S (2011) Role of YAP/ TAZ in mechanotransduction. Nature 474: 179-183.

Etienne-Manneville S, Hall A (2003) Cdc42 regulates GSK-3 $\beta$ and adenomatous polyposis coli to control cell polarity. Nature 421: 753-755.

Finch-Edmondson ML, Strauss RP, Passman AM, Sudol M, Yeoh GC, Callus BA (2015) TAZ protein accumulation is negatively regulated by YAP abundance in mammalian cells. J Biol Chem 290: 27928-27938.

Flannery CR, Zollner R, Corcoran C, Jones AR, Root A, Rivera-Bermúdez MA, Blanchet T, Gleghorn JP, Bonassar LJ, Bendele AM, Morris EA, Glasson SS (2009) Prevention of cartilage degeneration in a rat model of osteoarthritis by intraarticular treatment with recombinant lubricin. Arthritis Rheum 60: 840847.

Foster CT, Gualdrini F, Treisman R (2012) Mutual dependence of the MRTF-SRF and YAP-TEAD pathways in cancer-associated fibroblasts is indirect and mediated by cytoskeletal dynamics. Genes Dev 26: 2361-2375.

Goto H, Nishio M, To Y, Oishi T, Miyachi Y, Maehama T, Nishina H, Akiyama H, Mak TW, Makii Y, Saito T, Yasoda A, Tsumaki N, Suzuki A (2018) Loss of Mob1a/bin mice results in chondrodysplasia due to YAP1/TAZ-TEAD-dependent repression of 
SOX9. Development 145: dev159244. DOI: 10.1242/ dev.159244.

Grogan SP, Duffy SF, Pauli C, Koziol JA, Su AI, D'Lima DD, Lotz MK (2013) Zone-specific gene expression patterns in articular cartilage. Arthritis Rheum 65: 418-428.

Guilak F, Ratcliffe A, Lane N, Rosenwasser MP, Mow VC (1994) Mechanical and biochemical changes in the superficial zone of articular cartilage in canine experimental osteoarthritis. J Orthop Res 12: 474-484.

He M, Zhou Z, Shah AA, Hong Y, Chen Q, Wan Y (2016) New insights into posttranslational modifications of Hippo pathway in carcinogenesis and therapeutics. Cell Div 11: 491. DOI: 10.1186/ s13008-016-0013-6.

Hossain Z, Ali SM, Ko HL, Xu J, Ng CP, Guo K, Qi Z, Ponniah S, Hong W, Hunziker W (2007) Glomerulocystic kidney disease in mice with a targeted inactivation of Wwtr1. Proc Natl Acad Sci U S A 104: 1631-1636.

Hosseini SM, Wu Y, Ito K, van Donkelaar CC (2014) The importance of superficial collagen fibrils for the function of articular cartilage. Biomech Model Mechanobiol 13: 41-51.

Huang W, Lv X, Liu C, Zha Z, Zhang H, Jiang Y, Xiong Y, Lei Q-Y, Guan K-L (2012) The N-terminal phosphodegron targets TAZ/WWTR1 protein for SCF $\beta$-TrCP-dependent degradation in response to phosphatidylinositol 3-kinase inhibition. J Biol Chem 287: 26245-26253.

Kaan HYK, Chan SW, Tan SKJ, Guo F, Lim CJ, Hong W, Song H (2017) Crystal structure of TAZTEAD complex reveals a distinct interaction mode from that of YAP- TEAD complex. Sci Rep 7: 1-11.

Khan IM, Salter DM, Bayliss MT, Thomson BM, Archer CW (2001) Expression of clusterin in the superficial zone of bovine articular cartilage. Arthritis Rheum 44: 1795-1799.

Kimura TE, Duggirala A, Smith MC, White S, SalaNewby GB, Newby AC, Bond M (2016) The Hippo pathway mediates inhibition of vascular smooth muscle cell proliferation by cAMP. J Mol Cell Cardiol 90: 1-10.

Koyama E, Saunders C, Salhab I, Decker RS, Chen I, Um H, Pacifici M, Nah HD (2014) Lubricin is required for the structural integrity and post-natal maintenance of TMJ. J Dent Res 93: 663-670.

Loeser RF, Collins JA, Diekman BO (2016) Ageing and the pathogenesis of osteoarthritis. Nat Rev Rheumatol 12: 412-420.

Low BC, Pan CQ, Shivashankar GV, Bershadsky A, Sudol M, Sheetz M (2014) YAP/TAZ as mechanosensors and mechanotransducers in regulating organ size and tumor growth. FEBS Lett 588: 2663-2670.

Malda J, Hoope ten W, Schuurman W, van Osch GJVM, van Weeren PR, Dhert WJA (2010) Localization of the potential zonal marker clusterin in native cartilage and in tissue-engineered constructs. Tissue Eng Part A 16: 897-904.

Mallein-Gerin F, Ruggiero F, Garrone R (1990) Proteoglycan core protein and type II collagen gene expressions are not correlated with cell shape changes during low density chondrocyte cultures. Differentiation 43: 204-211.

Matsui $Y$, Hasegawa M, Iino T, ImanakaYoshida K, Yoshida T, Sudo A (2018) Tenascin-C prevents articular cartilage degeneration in murine osteoarthritis models. Cartilage 9: 80-88.

McNary SM, Athanasiou KA, Reddi AH (2014) Transforming growth factor $\beta$-induced superficial zone protein accumulation in the surface zone of articular cartilage is dependent on the cytoskeleton. Tissue Eng Part A 20: 921-929.

Medjkane S, Perez-Sanchez C, Gaggioli C, Sahai E, Treisman R (2009) Myocardin-related transcription factors and SRF are required for cytoskeletal dynamics and experimental metastasis. Nat Cell Biol 11: 257-268.

Miesfeld JB, Gestri G, Clark BS, Flinn MA, Poole RJ, Bader JR, Besharse JC, Wilson SW, Link BA (2015) YAP and TAZ regulate retinal pigment epithelial cell fate. Development 142: 3021-3032.

Morin-Kensicki EM, Boone BN, Howell M, Stonebrake JR, Teed J, Alb JG, Magnuson TR, O'Neal W, Milgram SL (2006) Defects in yolk sac vasculogenesis, chorioallantoic fusion, and embryonic axis elongation in mice with targeted disruption of YAP65. Mol Cell Biol 26: 77-87.

Moya IM, Halder G (2018) Hippo-YAP/TAZ signalling in organ regeneration and regenerative medicine. Nat Rev Mol Cell Biol 20: 211-226.

Okamura N, Hasegawa M, Nakoshi Y, Iino T, Sudo A, Imanaka-Yoshida K, Yoshida T, Uchida A (2010) Deficiency of tenascin- $C$ delays articular cartilage repair in mice. Osteoarthritis Cartilage 18: 839-848.

Pacifici M, Iwamoto M, Golden EB, Leatherman JL, Lee Y-S, Chuong C-M (1993) Tenascin is associated with articular cartilage development. Dev Dyn 198: 123-134.

Papakonstani EA, Stournaras C (2002) Association of PI-3 kinase with PAK1 leads to actin phosphorylation and cytoskeletal reorganization. Mol Biol Cell 13: 2946-2962.

Parreno J, Nabavi Niaki M, Andrejevic K, Jiang A, Wu P-H, Kandel RA (2017) Interplay between cytoskeletal polymerization and the chondrogenic phenotype in chondrocytes passaged in monolayer culture. J Anat 230: 234-248.

Parreno J, Raju S, Niaki MN, Andrejevic K, Jiang A, Delve E, Kandel R (2014) Expression of type I collagen and tenascin $C$ is regulated by actin polymerization through MRTF in dedifferentiated chondrocytes. FEBS Lett 588: 3677-3684.

Parreno J, Raju S, Wu P-H, Kandel RA (2016) MRTF-A signaling regulates the acquisition of the contractile phenotype in dedifferentiated chondrocytes. Matrix Biol 62: 3-14.

Pfaffl MW (2001) A new mathematical model for relative quantification in real-time RT-PCR. Nucleic Acids Res 29: 1-6.

Pfander D, Heinz N, Rothe P, Carl HD, Swoboda B (2004) Tenascin and aggrecan expression by articular 
chondrocytes is influenced by interleukin 1: a possible explanation for the changes in matrix synthesis during osteoarthritis. Ann Rheum Dis 63: 240-244.

Piersma B, Bank RA, Boersema M (2015) Signaling in Fibrosis: TGF- $\beta$, WNT, and YAP/TAZ Converge. Front Med 2: 1138. DOI: 10.3389/fmed.2015.00059.

Plouffe SW, Lin KC, Moore JL 3rd, Tan FE, Ma S, Ye Z, Qiu Y, Ren G, Guan K-L (2018) The Hippo pathway effector proteins YAP and TAZ have both distinct and overlapping functions in the cell. J Biol Chem 293: 11230-11240.

Pritzker K, Gay S, Jimenez S, Ostergaard K, Pelletier J, Revell P, Salter D, Vandenberg W (2006) Osteoarthritis cartilage histopathology: grading and staging. Osteoarthritis Cartilage 14: 13-29.

Reginensi A, Scott RP, Gregorieff A, BagherieLachidan M, Chung C, Lim D-S, Pawson T, Wrana J, McNeill H (2013) YAP- and Cdc42-dependent nephrogenesis and morphogenesis during mouse kidney development. PLoS Genet 9: e1003380. DOI: 10.1371/journal.pgen.1003380.

Rhee DK, Marcelino J, Baker M, Gong Y, Smits P, Lefebvre V, Jay GD, Stewart M, Wang H, Warman ML, Carpten JD (2005) The secreted glycoprotein lubricin protects cartilage surfaces and inhibits synovial cell overgrowth. J Clin Invest 115: 622-631.

Ruan MZC, Erez A, Guse K, Dawson B, Bertin T, Chen Y, Jiang MM, Yustein J, Gannon F, Lee BHL (2013) Proteoglycan 4 expression protects against the development of osteoarthritis. Sci Transl Med 5: 176ra34. DOI: 10.1126/scitranslmed.3005409.

Schmidt TA, Schumacher BL, Klein TJ, Voegtline MS, Sah RL (2004) Synthesis of proteoglycan 4 by chondrocyte subpopulations in cartilage explants, monolayer cultures, and resurfaced cartilage cultures. Arthritis Rheum 50: 2849-2857.

Schumacher BL, Block JA, Schmid TM, Aydelotte MB, Kuettner KE (1994) A novel proteoglycan synthesized and secreted by chondrocytes of the superficial zone of articular cartilage. Arch Biochem Biophys 311: 144-152.

Sophia Fox AJ, Bedi A, Rodeo SA (2009) The basic science of articular cartilage: structure, composition, and function. Sports Health 1: 461-468.

Speight P, Kofler M, Szászi K, Kapus A (2016) Context-dependent switch in chemo/ mechanotransduction via multilevel crosstalk among cytoskeleton-regulated MRTF and TAZ and TGF $\beta$ regulated Smad3. Nat Commun 7: 1-17.

Thomasy SM, Morgan JT, Wood JA, Murphy CJ, Russell P (2013) Substratum stiffness and latrunculin $\mathrm{B}$ modulate the gene expression of the mechanotransducers YAP and TAZ in human trabecular meshwork cells. Exp Eye Res 113: 66-73.

Totaro A, Castellan M, Battilana G, Zanconato F, Azzolin L, Giulitti S, Cordenonsi M, Piccolo S (2017) YAP/TAZ link cell mechanics to notch signalling to control epidermal stem cell fate. Nat Commun 8: 15206. DOI: $10.1038 /$ ncomms15206.

Varelas X, Samavarchi-Tehrani P, Narimatsu M, Weiss A, Cockburn K, Larsen BG, Rossant J, Wrana
JL (2010) The crumbs complex couples cell density sensing to hippo-dependent control of the TGF- $\beta$ Smad Pathway. Dev Cell 19: 831-844.

Wada KI, Itoga K, Okano T, Yonemura S, Sasaki H (2011) Hippo pathway regulation by cell morphology and stress fibers. Development 138: 3907-3914.

Xin M, Kim Y, Sutherland LB, Murakami M, Qi X, McAnally J, Porrello ER, Mahmoud AI, Tan W, Shelton JM, Richardson JA, Sadek HA, Bassel-Duby R (2013) Hippo pathway effector YAP promotes cardiac regeneration. Proc Natl Acad Sci U S A 110: 13839-13844.

Yarmola EG, Somasundaram T, Boring TA, Spector I, Bubb MR (2000) Actin-latrunculin A structure and function: differential modulation of actin-binding protein function by latrunculin A. J Biol Chem 275: 28120-28127.

Zhao B, Li L, Lu Q, Wang LH, Liu CY, Lei Q, Guan KL (2011) Angiomotin is a novel Hippo pathway component that inhibits YAP oncoprotein. Genes Dev 25: 51-63.

\section{Discussion with Reviewer}

Jessica Bertrand: What is the relevance of F-actin remodelling in SZCs in vivo?

Authors: While F-actin remodelling in the SZ has not been investigated in vivo, it is possible to speculate from results obtained from in vitro experiments that exposure of SZCs to growth factors and inflammatory cytokines, such as TGF- $\beta$ and IL-1 $\beta$, can alter actin dynamics. Changes in the concentration of these soluble factors present in the synovial fluid may influence the phenotype of the chondrocytes in the SZ through altering actin dynamics and, ultimately, downstream gene transcription through actinregulated pathways.

Jessica Bertrand: What are the effects of YAP/TAZ down regulation in vivo and under which conditions does this happen?

Authors: An in vivo study conducted by Deng et al. (2018, additional reference) in mice observed decreased endogenous YAP expression in cartilage with age. This study observed YAP expression throughout the thickness of articular cartilage, which appeared to inversely correlate with cartilage maturation as decreases were observed with age. Decreases in YAP expression were also observed with surgically induced OA, leading the authors to conclude that YAP expression is highly correlated to OA pathogenesis. This argument was further strengthened by generating mutant mice with inactive Hippo signalling, leading to elevated levels of YAP in the articular cartilage. This had a chondroprotective effect against the development of OA whether it was induced by anterior cruciate ligament transection or destabilisation of the medial meniscus. The study also demonstrated decreased YAP/TAZ protein levels with exposure to inflammatory cytokines TNF- $\alpha$ and 
IL-1 $\beta$ in primary chondrocytes (Deng et al., 2018, additional reference). It is important to note that Deng et al. (2018, additional reference) examined the entire thickness of articular cartilage in vivo and used primary chondrocytes isolated from full-thickness cartilage, which is different from the present study that focused on SZ cells. To the best of our ability, we did not find any study describing the effects of YAP/TAZ downregulation in the SZ of cartilage and, therefore, we can only speculate.

\section{Additional Reference}

Deng Y, Lu J, Li W, Wu A, Zhang X, Tong W, Ho KK, Qin L, Song H, Mak KK (2018) Reciprocal inhibition of YAP/TAZ and $N F-\kappa B$ regulates osteoarthritic cartilage degradation. Nat Commun 9: 4564. DOI: 10.1038/s41467-018-07022-2.

Editor's note: The Scientific Editor responsible for this paper was Christine Hartmann. 